\title{
Забнина Г.Г.
}

\section{ОЦЕНКА ЭФФЕКТИВНОСТИ ИСПОЛЬЗОВАНИЯ СРЕДСТВ РЕГИОНАЛЬНОГО БЮДЖЕТА БЕЛГОРОДСКОЙ ОБЛАСТИ}

Белгородский государственный национальный исследовательский университет ул. Победы, 85, г. Белгород, 308015, Россия

e-mail: zabnina_g@bsu.edu.ru

\begin{abstract}
Аннотация
Эффективное развитие региона является основополагающей задачей местных органов власти. На современном этапе существует множество подходов для ее осуществления, одним из которых является грамотная оценка использования бюджета. C ее помощью определяются принципы результативности использования бюджетных средств, выстраиваются различные механизмы контроля и управления. В работе рассмотрены основы бюджета Белгородской области и сделан вывод о возрастании обязательств по расходам. Доказано, что применение бюджетной политики оказывает колоссальное влияние на качество осуществления стратегических целей региона, а также способствует грамотному регулированию социальных процессов, и гармоничному соотношению доходной и расходной частей бюджета.
\end{abstract}

Ключевые слова: бюджет, бюджетные ассигнования, региональный бюджет, финансовая система, межбюджетные отношения, фонды денежных средств, финансовый механизм.

Информация для цитирования: Забнина Г.Г. Оценка эффективности использования средств регионального бюджета Белгородской области // Научный результат. Экономические исследования. 2021. Т. 7. № 2. С. 58-65. DOI: $10.18413 / 2409-1634-2021-7-2-0-6$

\section{Galina G. Zabnina \\ ASSESSMENT OF THE EFFICIENCY OF THE USE OF THE REGIONAL BUDGET OF THE BELGOROD REGION}

\author{
Belgorod State National Research University \\ 85 Pobedy St., Belgorod, 308015, Russia \\ e-mail: zabnina_g@bsu.edu.ru
}

\begin{abstract}
The effective development of the region is a fundamental task of local authorities. At the present stage, there are many approaches for its implementation, one of which is a competent assessment of the use of the budget. With its help, the principles of the effectiveness of the use of budget funds are determined, various control and management mechanisms are built. The paper considers the basics of the budget of the
\end{abstract}


Belgorod region and concludes that there is an increase in expenditure obligations. It is proved that the application of budget policy has a huge impact on the quality of the implementation of the strategic goals of the region, and also contributes to the competent regulation of social processes, and a harmonious ratio of the revenue and expenditure parts of the budget.

Key words: budget; budget allocations; regional budget; financial system; interbudgetary relations; funds of funds; financial mechanism

Information for citation: Zabnina G. G. "Assessment of the effectiveness of the use of the regional budget of the Belgorod region, Research Result. Economic Research, 7(2), 58-65, DOI: 10.18413/2409-1634-2021-7-2-0-6

\section{Введение}

Бюджетная политика региона представляет собой комплекс мероприятий в сфере организации бюджетных отношений, социально- экономическая сущность которой состоит в выборе стратегии регулирования социальных процессов, а также управления налоговыми и бюджетными отношениями, региональными финансами [Бюджетный кодекс Российской Федерации от 31.07.1998]. Результатом этого становится обеспечение области денежными средствами для ее четкого функционирования и осуществления поставленных задач. Бюджетная политика региона является центром экономической политики в целом и отражает взаимоотношения различных общественных институтов и населения в сфере финансов.

Бюджетный процесс Белгородской области включает в себя деятельность органов государственной власти, которая заключается в рассмотрении проектов бюджетов, утверждении и исполнении бюджета области, бюджетов муниципальных образований, контроле за их исполнением, ведении бюджетного учета, подготовке внешнего аудита, проверки и утверждении бюджетной отчетности [Забнина Г.Г., Сорокин И.И., 2019]. Основными задачами органов государственной власти региона на ближайшую перспективу являются сохранение социальной стабильности, стимулирование инвестиционной деятельности и повышения спроса на инновации в экономике. Эти меры должны способство- вать увеличению налогового потенциала и формированию стабильной доходной базы бюджета области.

\section{Основная часть}

Основные направления бюджетной и налоговой политики на долгосрочную перспективу сохраняют преемственность реализуемых мер, направленных на повышение эффективности использования доходного потенциала для обеспечения заданных темпов экономического роста, безусловное исполнение принятых социальных обязательств, финансовое обеспечение реализации приоритетных для региона задач, поддержку предпринимательской и инвестиционной активности. Их базовым принципом является обеспечение долгосрочной сбалансированности областного бюджета, решение текущих и перспективных задач наиболее эффективным способом [О мерах по реализации закона Белгородской области от 13 декабря 2019 года № 431].

Региональный бюджет - один из основных инструментов, оказывающих влияние государственных органов власти на социально-экономические процессы в регионе. Его действие отражается и в самом процессе формирования бюджета, и в процессе дальнейшего использования для реализации различных социальноэкономических расходов.

В Бюджетном кодексе Российской Федерации дается следующее определение расходов бюджета: «Расходы бюджета - 
выплачиваемые из бюджета денежные средства, за исключением средств, являющихся в соответствии с настоящим Кодексом источниками финансирования дефицита бюджета» [Бюджетный кодекс Российской Федерации от 31.07.1998].

Министерством финансов Российской Федерации была разработана методология, позволяющая рассмотреть результаты, полученные субъектами Российской Федерации в части улучшения эффективности расходов бюджета. Она включает следующие показатели: ОС1 и ОС2, которые позволяют детально оценить эффек-

тивность региональных фондов [Об утверждении методики проведения оценки результатов]:

1) ОС1 - отношение дефицита бюджета к доходам без учета объема безвозмездных поступлений;

2) ОС2 - отношение государственного долга (за вычетом выданных гарантий) к доходам бюджета без учета объема безвозмездных поступлений.

Для оценки эффективности использования средств регионального бюджета Белгородской области, рассмотрим динамику областного бюджета.

Таблица 1

Основные характеристики областного бюджета на 2018 - 2022 года, тыс. руб.

Table 1

Main characteristics of the regional budget for 2018 - 2022, thousand rubles.

\begin{tabular}{|l|c|c|c|c|c|}
\hline \multicolumn{1}{|c|}{ Показатель } & \multicolumn{1}{|c|}{2018} & 2019 & 2020 & 2021 & 2022 \\
\hline Доходы & 93654982,0 & 87939982,5 & 97530093,3 & 94717674,7 & 95120854,9 \\
\hline $\begin{array}{l}\text { в т.ч. Налоговые } \\
\text { и неналоговые } \\
\text { доходы }\end{array}$ & 73491697,0 & 70667945,0 & 80661563,0 & 82208640,0 & 85362176,0 \\
\hline $\begin{array}{l}\text { в т.ч. Безвозмезд- } \\
\text { ные поступления }\end{array}$ & 20163285,0 & 17272037,5 & 16868530,3 & 12509034,7 & 9758678,9 \\
\hline Расходы & 85558198,0 & 91549778,5 & 103916588,0 & 99669780,8 & 100957789,1 \\
\hline $\begin{array}{l}\text { Дефицит област- } \\
\text { ного бюджета } \\
\text { (профицит) }\end{array}$ & 8096748,0 & 3609796,0 & 6386494,7 & 4952106,1 & 5836934,2 \\
\hline $\begin{array}{l}\text { Верхний предел } \\
\text { государственного } \\
\text { внутреннего } \\
\text { долга }\end{array}$ & 35334067,0 & 34125268,0 & 29595005,0 & 28959222,0 & 28463131,0 \\
\hline $\begin{array}{l}\text { Верхний предел } \\
\text { государственного } \\
\text { внутреннего дол- } \\
\text { га по гос. гаран- } \\
\text { тиям Белгород- } \\
\text { ской области }\end{array}$ & 6275556,0 & 5073388,0 & 3410387,0 & 3005387,0 & 3145819,0 \\
\hline
\end{tabular}

\section{Источник: составлено автором по материалам 10}

Так, для Белгородской области общий прогноз доходов на 2020 год составляет 97,5 млрд. рублей. Расходы же прогнозируются в объеме 103,9 млрд. рублей.
Предполагается, что собственные доходы областного бюджета в 2020 году достигнут 80,7 млрд рублей, 16,8 млрд рублей регион получит в качестве безвозмездных поступлений из федерального центра.

Таблица 2 
Основные коэффициенты эффективности использования средств областного бюджета Белгородской области за период 2018-2020 гг. и на плановый период 2021-2022 гг., \%

Table 2

The main coefficients of the effectiveness of the use of funds from the regional budget

of the Belgorod region for the period 2018-2020 and for the planning period 2021-2022,\%

\begin{tabular}{|l|l|l|l|l|l|l|l|}
\hline $\begin{array}{c}\text { Обозна- } \\
\text { чение }\end{array}$ & Формула & 2018 & 2019 & 2020 & 2021 & 2022 & \multicolumn{1}{|}{ Пояснения } \\
\hline ОС1 & $\begin{array}{l}\text { ОС1 Деф } \\
=\frac{\text { Д-БП }}{* 100 \%}\end{array}$ & 11,0 & 5,1 & 7,9 & 6,0 & 6,8 & $\begin{array}{l}\text { Деф - размер дефицита } \\
\text { бюджета; } \\
\text { Д- доходы бюджета; } \\
\text { БП - безвозмездные по- } \\
\text { ступления вюджет субъек- } \\
\text { та РФ; }\end{array}$ \\
\hline ОС2 & $\begin{array}{l}\text { ОС2 } \\
=\frac{\text { ГД-Гар }}{\text { Д-БП }} \\
* 100 \%\end{array}$ & 39,5 & 41,1 & 32,5 & 31,6 & 29,7 & $\begin{array}{l}\text { ГД - размер государствен- } \\
\text { ного долга; } \\
\text { Гар - государственный долг } \\
\text { в части предоставленных } \\
\text { государственных гарантий. }\end{array}$ \\
\hline
\end{tabular}

Источник: составлено автором по материалам [Об утверждении методики проведения оценки результатов]

Проанализировав данные таблиц 1 и 2, можно сделать вывод, что общие обязательства по расходам растут довольно высокими темпами. Показатель ОС1 отражает долю бюджетного дефицита в чистых доходах и говорит о положительной тенденции, результат которой будет достигнут к 2022 году, показатель которого снизится на 62,1\% по сравнению с 2018 годом.

Аналогичная ситуация наблюдается для ОС2, характеризующего степень покрытия государственного долга доходами бюджета. Данный показатель снижается из года в год, начиная 39,5 \% в 2018 году, заканчивая 29,7 \% в 2022 г., что отражает положительную тенденцию.

Так, разработка бюджетной политики Белгородской области начинается с установления фундаментальных основ бюджета. Первоочередно формулируются конкретные направления использования бюджета в интересах общества и Правительства, в которых расходно-доходные статьи занимают главенствующую роль в управлении бюджетом [Белгородская областная Дума, 2021].

Доходная устойчивость региональной экономики зависит от многих факто- ров и в то же время лежит в основе бюджетирования. Одним из основополагающих факторов, влияющих на увеличение региональных доходов, является бизнес, который платит большую часть налогов в бюджет. [Тамов Р.М., Ваганова О.В., 2020]. Он создает рабочие места, способствуя увеличению налоговых поступлений по налогу на прибыль, также большой объем приходится на налог на имущество, акцизы и т. д. Таким образом, главными источниками региональной казны на 20202022 года остаются налог на прибыль организаций, его доля составит 45\% (36,3 млрд рублей), налог на доходы физических лиц (22\% или 17,9 млрд рублей), налог на имущество (10\% или 8 млрд. рублей) и акцизы (10\% или 7,9 млрд рублей) [РБК, 2021].

На территории Белгородской области реализуется комплекс мер, направленный на развитие инвестиционного потенциала региона и инновационной экономики [Baганова О.В., 2017]. Сегодня большое внимание отводится обеспечению территории новыми строительными объектами, поддержке малых инвестиционных предприятий, содействию развития инноваций. По- 
литика региона направлена на устранение бюрократических препятствий для получения кредитов и субсидий, а, следовательно, дают экономическую стабильность и финансовую устойчивость области [Соловьева Н.Е., Забнина Г.Г., Ботнарь С.А., Лютых М.П., Ломова М.Э., 2019]. Не остается в стороне вопрос роста заработной платы и реализации мероприятий, направленных на содействие занятости населения области. В области активно реализуются программы социальной поддержки населению, обеспечения социальнополитической стабильности [Глаголев С. Н., Ваганова О. В., 2013].

Отдельной статьей расходов бюджета выделены расходы на реализацию 9 национальных проектов. Наибольшую часть расходов придется на поддержку демографии, здравоохранения, образования и улучшение городской среды.

В национальный проект «Демография» входят следующие направления:

- Материальная поддержка семей при рождении детей;

-Стимулирование рождаемости первенцев в молодых семьях (включает единовременные выплаты студенческим семьям в размере 100 тыс. руб., компенсация на продукты детского питания, выделение денежных средств на улучшение условий жилья)

- Создание условий дошкольного образования для детей в возрасте до трех лет для возможности выхода на работу матерей;

- Поддержка граждан старшего поколения, включающая повышение качества жизни;

- Пропаганда здорового образа жизни, включая создание условий для занятий физической культурой и спортом, в том числе повышение уровня обеспеченности населения объектами спорта.

В результате ее реализации планируется добиться следующих показателей, приведенных в таблице 3 .

Таблица 3

Показатели (индикаторы) национального проекта «Демография» за 2019-2022 гг.

Table 3

Indicators (indicators) of the national project «Demography» for 2019-2022.

\begin{tabular}{|c|c|c|c|c|c|}
\hline $\begin{array}{c}\text { Показатель (ин- } \\
\text { дикатор) }\end{array}$ & $\begin{array}{l}\text { Ед. } \\
\text { изм. }\end{array}$ & $\begin{array}{c}\text { Фактические } \\
\text { результаты } \\
\text { за } 2019 \text { год }\end{array}$ & $\begin{array}{c}\text { Фактические } \\
\text { результаты } \\
\text { за } 2020 \text { год }\end{array}$ & $\begin{array}{l}\text { Ожидаемые } \\
\text { результаты } \\
\text { за } 2021 \text { год }\end{array}$ & $\begin{array}{l}\text { Ожидаемые } \\
\text { результаты } \\
\text { за } 2022 \text { год }\end{array}$ \\
\hline $\begin{array}{l}\text { Ожидаемая про- } \\
\text { должительность } \\
\text { жизни }\end{array}$ & $\begin{array}{l}\text { число } \\
\text { лет }\end{array}$ & 74,9 & 75,6 & 75,7 & 76,4 \\
\hline $\begin{array}{l}\text { Суммарный } \\
\text { эфо- } \\
\text { даемоциент }\end{array}$ & $\begin{array}{l}\text { Коэф- } \\
\text { эф- } \\
\text { фици- } \\
\text { ент } \\
\end{array}$ & 1,6 & 1,63 & 1,6 & 1,6 \\
\hline $\begin{array}{l}\text { Общий коэффи- } \\
\text { циент смертности } \\
\text { населения на } \\
1000 \text { человек } \\
\end{array}$ & $\begin{array}{l}\text { Коэф- } \\
\text { эф- } \\
\text { фици- } \\
\text { ент } \\
\end{array}$ & 13,0 & 13,0 & 12,8 & 12,7 \\
\hline $\begin{array}{l}\text { Коэффициент } \\
\text { естественной } \\
\text { убыли (прироста) }\end{array}$ & $\begin{array}{l}\text { про- } \\
\text { милле }\end{array}$ & $-2,6$ & $-2,5$ & $-2,4$ & $-2,3$ \\
\hline
\end{tabular}

Согласно данным таблицы, в 2022 году по сравнению с 2019 ожидается увеличение продолжительности жизни на 1,5 года. Суммарный коэффициент рождаемо- сти составит 1,626 , что больше со сравниваем периодом на 0,048. Кроме того, ожидается снижение коэффициента смертности на 0,3 . 
Национальный проект «Здравоохранение»»» предполагает снижение показателей смертности населения трудоспособного возраста (до 350 случаев на 100 тыс. населения), смертности от болезней системы кровообращения (до 450 случаев на 100 тыс. населения), смертности от новообразований, в том числе от злокачественных (до 185 случаев на 100 тыс. населения), младенческой смертности (до 4,5 случая на 1 тыс. родившихся детей) на территории страны. Что касается Белгородской области в целом, мероприятия в рамках данного проекта будут направлены на повышение доступности и качества первичной медицинской помощи всем гражданам Белгородской области, борьбу с сердечнососудистыми и онкологическими заболеваниями, развитие детского здравоохранения, устранение кадрового дефицита медицинских работников. В связи с существующей проблемой перегруженности врачей на скорой помощи планируется включить неотложные бригады семейных врачей. В 2020 году расширится список категорий граждан, имеющих право на льготное получение лекарственных средств. На это будет выделено в 2020 году 15139112,9 тыс. рублей [Об утверждении государственной программы Белгородской области].

В рамках реализации указа Президента Российской Федерации от 07.05.2018 «О национальных целях и стратегических задачах развития России на период до 2024 года» был разработан национальных проект «Образование». Приоритетными направлениями в этой сфере стали действия по созданию современной образовательной среды для обучающихся, развитие дополнительного образования, мобилизация ресурсов социальных институтов в воспитании подрастающего поколения с учетом региональных особенностей. В этой связи была разработана структура проекта, в которую вошли такие программы как «Современная школа», «Успех каждого ребенка», «Цифровая образовательная среда», «Молодые профессиона- лы», «Учитель будущего» и т.д., которые активно реализуются на территории белгородской области и приносят свои плоды.

Касаемо реализации программы «Формирование современной городской среды на территории Белгородской области», будет реализовано не менее 216 мероприятий по благоустройству общественных территорий, увеличено количество доли городов с благоприятной средой до 60 процентов. Объем финансирования в период с 2020 по 2022 года составит 236360,8 тыс. руб.

\section{Заключение}

Анализируя вышесказанное можно констатировать тот факт, что реализация бюджетной политики позволит:

- обеспечить сбалансированность и долгосрочную стабильность региональной бюджетной системы;

- совершенствование межбюджетных отношений в сотрудничестве с местными органами власти;

- сформировать областной бюджет на основе государственных программ как инструмента повышения эффективности бюджетных расходов;

- перейти к программной структуре расходов бюджетов;

- повысить эффективность предоставления государственных услуг и закупок;

-повысить открытость и прозрачность управления государственными финансами области.

Анализ оценки эффективности использования бюджетных средств показывает, что в период 2018-2022 гг. степень покрытия государственного долга будет иметь положительную тенденцию, кроме того, ожидается снижение обязательств по расходам. Результаты социальноэкономического развития области свидетельствуют о том, что бюджетная политика Белгородской области соответствуют стратегическим целям региона и в целом является эффективной. Это обусловлено грамотным построением регулирования социальных процессов, управле- 
ния налоговыми и бюджетными отношениями, соотношением доходной и расходной частей бюджета, а также реализации национальных проектов.

\section{Список литературы}

1. Бюджетный кодекс Российской Федерации от 31.07.1998 № 145-Ф3 (ред. от 02.08.2019) (с изм. и доп., вступ. в силу с 01.09.2019) [Электронный ресурс]: // Консультант Плюс: справочная правовая система. Разд. «Законодательство». Информ. Банк «Версия Проф». (дата обращения: 31.04.2021).

2. Налоговый кодекс Российской Федерации (НК РФ) от 31 июля 1998 года № 146Ф3 [Электронный ресурс]: // Консультант Плюс: справочная правовая система. Разд. «Законодательство». Информ. Банк «Версия Проф».

3. Об утверждении методики проведения оценки результатов, достигнутых субъектами Российской Федерации в сфере повышения эффективности бюджетных расходов, и динамики данных результатов [Электронный ресурс]: Приказ Министерства финансов РФ от 26.07.2013 г. № 75-н (с изм. и доп.)// Консультант Плюс: справочная правовая система. Разд. «Законодательство». Информ. Банк «Версия Проф». (дата обращения: 31.04.2021).

4. Об утверждении государственной программы Белгородской области "Развитие здравоохранения Белгородской области": Постановление (с изменениями на 16 декабря 2019 года) от 16 декабря 2013 года № 524-пп [Электронный ресурс]: // Консультант Плюс: справочная правовая система. Разд. «Законодательство». Информ. Банк «Версия Проф». (дата обращения: 31.04.2021).

5. О мерах по реализации закона Белгородской области от 13 декабря 2019 года № 431 «Об областном бюджете на 2020 год и на плановый период 2021 и 2022 годов»: Постановлениеот 10 февраля 2020 года № 52-пп [Электронный ресурс]: // Консультант Плюс: справочная правовая система. Разд. «Законодательство». Информ. Банк «Версия Проф». (дата обращения: 31.04.2021).

6. Белгородская областная Дума, 2021. [Электронный ресурс]: [офиц. сайт]. - Режим доступа:

https://www.belduma.ru/news/detail.php?ID=389 49. (дата обращения: 31.04.2021).
7. Ваганова О.В., 2017. Методологические аспекты формирования механизмов интеграционного взаимодействия субъектов в региональных инновационных системах: диссертация ... доктора экономических наук: 08.00.05 / Ваганова O.В.; [Место защиты: ФГБОУ ВО Санкт-Петербургский государственный экономический университет], 2017.

8. Глаголев С. Н., Ваганова О. В., 2013. Специфические детерминанты структурирования экономики с учетом фактора интеграции. Всемирный журнал Прикладных Наук. 2013. 24 (10): 1322-1329.

9. Забнина Г.Г., Сорокин И.И., 2019. Сущность бюджетной политики региона / Научный результат. Экономические исследования. - Т.5, №2, 2019.

10. Камысовская, С. В. Анализ региональных бюджетов РФ [Текст]: учеб.пособие / С.В. Камысовская, Т.В. Захарова, Н.Н. Попова. - М.: Форум, 2019: 288.

11. Климентьева Н.М., 2019. Управление ликвидностью бюджетных средств, для наращивания финансового потенциала регионов России [Текст] /Н.М. Климентьева, В.Е. Ульянкин // Финансовая экономика. - М.: Некоммерческий фонд содействия развитию экономической науки и образования «Экономика», 2019: 253-255.

12. Соловьева Н.Е., Забнина Г.Г., 2019. Бюджетно-налоговая политика [Текст]: учебное пособие/ Н.Е. Соловьева, Г.Г. Забнина. Белгород: ИД «Белгород» НИУ «БелГУ», 2019: 76.

13. Соловьева Н.Е., Забнина Г.Г., Ботнарь С.А., Лютых М.П., Ломова М.Э., 2019. Сравнительный анализ налогового потенциала Белгородской и Курской областей и уровня обеспеченности региональных бюджетов финансовыми ресурсами // Экономика и предпринимательство. 2019. № 7 (108). С. 310-313.

14. РБК, 2021. [Электронный ресурс]: [офиц. сайт]. - Режим доступа: https://chr.plus.rbc.ru/partners/5ddbd51c7a8aa993 cc4b183a. (дата обращения: 31.04.2021).

15. Тамов Р.М., Ваганова О.В., 2020. Организационно-экономический механизм реализации стратегии развития региона // Региональная экономика и управление: электронный научный журнал. 2020. № 3 (63). С. 17. 


\section{References}

1. Belgorod Regional Duma-official website (2021). [Electronic resource]. - Access mode:

https://www.belduma.ru/news/detail.php?ID=389 49. (accessed: 31.04.2021).

2. Glagolev S. N., Vaganova O. V. (2013). Specific determinants of the structuring of the economy taking into account the integration factor. World Journal of Applied Sciences. 2013. 24 (10): 1322-1329

3. Kamysovskaya, S. V. (2019). Analysis of regional budgets of the Russian Federation [Text]: textbook / S.V. Kamysovskaya, T.V. Zakharova, N.N. Popov. - M.: Forum, 2019: 288.

4. Klimentieva N.M. (2019). Management of the liquidity of budgetary funds to increase the financial potential of the regions of Russia [Text] / N.M. Klimentyeva, V.E. Ulyankin // financial economy. - M.: Non-profit foundation for promoting the development of economic science and education «Economics», 2019: 253-255.

5. On the approval of the methodology for assessing the results achieved by the constituent entities of the Russian Federation in the field of increasing the efficiency of budget expenditures, and the dynamics of these results [Electronic resource]: Order of the Ministry of Finance of the Russian Federation of July 26, 2013, №. 75-n (with amendments and add) // Consultant Plus: legal reference system. Sec. «Legislation». Inform. Bank «Version Prof.» (Accessed 31 April 2021).

6. On the approval of the state program of the Belgorod region «Development of health care in the Belgorod region»: Resolution (as amended on December 16, 2019) of December 16, 2013 № 524-pp [Electronic resource]: // Consultant Plus: reference legal system. Sec. «Legislation». Inform. Bank «Version Prof.»

7. On measures to implement the law of the Belgorod region of December 13, 2019 № 431 «On the regional budget for 2020 and for the planning period of 2021 and 2022»: Resolution of February 10, 2020 № 52-pp [Electronic resource]: // Consultant Plus: reference legal system. Sec. «Legislation». Inform. Bank «Version Prof.» (Accessed 31 April 2021).

8. RBC, (2021). [Electronic resource]: [official. website]. - Access mode: https://chr.plus.rbc.ru/partners/5ddbd51c7a8aa993 cc4b183a. (Accessed 31 April 2021).

9. Solovjeva, N.E., Zabnina, G.G. (2019). Fiscal policy [Text]: tutorial / N.E. Solovjeva,
G.G. Zabnina. - Belgorod: Publishing House «Belgorod» NRU «BelGU», 2019: 76.

10. Solovjeva N. E., Zabnina G. G., Botnar S. A., Lyutykh M. P., Lomova M. E. (2019). Comparative analysis of the tax potential of the Belgorod and Kursk regions and the level of provision of regional budgets with financial resources // Economics and entrepreneurship. 2019. No. 7 (108). pp. 310-313.

11. Tamov R. M., Vaganova O. V. (2020). Organizational and economic mechanism for implementing the regional development strategy // Regional Economics and Management: an electronic scientific journal. 2020. No. 3 (63). p. 17.

12. Tax Code of the Russian Federation (RF Tax Code) of July 31, 1998 № 146-FZ [Electronic resource]: // Consultant Plus: reference legal system. Sec. «Legislation». Inform. Bank «Version Prof.» (Accessed 31 April 2021).

13. The Budget Code of the Russian Federation of July 31, 1998 № 145-FZ (as amended on 08/02/2019) (as amended and supplemented, entered into force on 09/01/2019) [Electronic resource]: // Consultant Plus: reference legal system. Sec. «Legislation». Inform. Bank «Version Prof.» (Accessed 31 April 2021).

14. Vaganova O. V. (2017). Methodological aspects of the formation of mechanisms of integration interaction of subjects in regional innovation systems: dissertation ... doctor of Economics: 08.00.05 / Vaganova O. V.; [Place of defense: St. Petersburg State University of Economics], 2017.

15. Zabnina G.G., Sorokin I.I. (2019). The essence of the budgetary policy of the region / Research Result. Economic research. - Vol.5, No2, 2019.

Информация о конфликте интересов: авторы не имеют конфликта интересов для декларации.

Conflicts of Interest: the author has no conflict of interest to declare.

Забнина Г. Г., кандидат экономических наук, доцент кафедры инновационной экономики и финансов, НИУ «БелГУ», (г. Белгород, Россия)

Zabrina G. G., Candidate of Economic Sciences, Associate Professor, Department of Innovative Economics and Finance, Belgorod State National Research University (Belgorod, Russia) 